\title{
Conforto térmico de búfalas em sistema silvipastoril na Amazônia Oriental
}

\author{
Jamile Andréa Rodrigues da Silva(1), Airton Alencar de Araújo(2), José de Brito Lourenço Júnior ${ }^{(3)}$, \\ Núbia de Fátima Alves dos Santos ${ }^{(4)}$, Alexandre Rossetto Garcia( ${ }^{(5)}$ e Benjamim de Souza Nahúm ${ }^{(5)}$
}

\begin{abstract}
(1)Universidade Federal Rural da Amazônia (UFRA), Instituto de Saúde e Produção Animal, Avenida Presidente Tancredo Neves, no 2501, CEP 66077-901 Belém, PA. E-mail: jamileandrea@yahoo.com.br (2)Universidade Estadual do Ceará, Departamento de Zootecnia, Avenida Mister Hull, s/no , Campus do Pici, CEP 60021-970 Fortaleza, CE. E-mail: aaalencar2002@yahoo.com.br ${ }^{(3)}$ Universidade do Estado do Pará, Centro de Ciências Naturais e Tecnologia, Travessa Dr. Enéas Pinheiro, no 2.626, CEP 66095-100 Belém, PA. E-mail: joselourencojr@yahoo.com.br ${ }^{(4)}$ UFRA, Unidade Descentralizada de Paragominas, Rodovia PA 256, s/noำ Km 6, CEP 68625-970 Paragominas, PA. E-mail: nubiasaint@yahoo.com.br ${ }^{(5)}$ Embrapa Amazônia Oriental, Travessa Dr. Enéas Pinheiro, s/non , CEP 66095-100 Belém, PA. E-mail: argarcia@cpatu.embrapa.br, nahum@cpatu.embrapa.br
\end{abstract}

Resumo - O objetivo deste trabalho foi avaliar o efeito de um sistema silvipastoril no conforto térmico de 20 búfalas Murrah, das quais 10 criadas em piquetes sem sombra (SS) e 10 com sombreamento (CS) de Racosperma mangium, em Belém, PA. Os animais foram alimentados em pasto, com Urochloa humidicola, com acesso livre à água para beber e sal mineral. A cada três dias, foram mensuradas: temperatura do ar (TA), umidade relativa do ar (UR), temperatura de globo negro (TGN), temperatura retal (TR), frequências respiratória (FR) e cardíaca (FC), e a temperatura da superfície corporal (TSC), pela manhã (7h) e à tarde (13h). Os valores de TR, TSC, FR e FC foram maiores à tarde, especialmente no grupo SS. Mais altas no período menos chuvoso, a TR, TSC e FR apresentaram correlação linear positiva com a TA e o índice de temperatura e umidade (ITGU) e negativa com a UR. Tanto na estação mais chuvosa quanto na menos chuvosa, a FC apresentou correlações significativas positivas com a TA e ITGU e negativas com a UR, apenas no período mais chuvoso. A arborização da pastagem é eficiente para melhorar o conforto térmico das búfalas Murrah, principalmente à tarde.

Termos para indexação: índice de temperatura e umidade, somreamento, bioclimatologia, Bubalus bubalis, Racosperma mangium, fisiologia.

\section{Thermal comfort of female buffaloes in a silvipasture system in the eastern Amazon}

\begin{abstract}
The objective of this work was to evaluate the effects of a silvipasture system on the thermal comfort of 20 female buffaloes, from which 10 raised in under nonshaded paddocks (SS) and 10 in paddocks shaded by Racosperma mangium (CS), in Belém county, PA, Brazil. All animals were fed in pastures with Urochloa humidicola, and had free access to drinking water and mineral salt. Every three days, measurements were made for air temperature (TA), relative humidity (UR), black globe temperature (TGN), rectal temperature (TR), respiratory rate (FR), heart rate (FC), and body surface temperature (TSC), in the morning (7 AM) and in the afternoon (1 PM). The values of TR, TSC, RR and FR, mainly for the SS group, were higher in the afternoon. The TR, TSC and FR showed a significant and positive correlation with TA and the temperature and humidity index (ITGU), and a negative correlation with UR. These correlations were higher for the less rainy period. The FR showed significant and positive correlations with TA and ITGU, during both the most and the less rainy seasons, and negative correlations with UR only in the rainy season. The forestation of pasture areas is efficient to increase the thermal comfort for Murrah females, especially in the afternoon.
\end{abstract}

Index terms: temeratura and humidity index, shading, bioclimatology, Bubalus bubalis, Racosperma mangium, physiology.

\section{Introdução}

O rebanho bubalino brasileiro é de cerca de 3,5 milhões de animais, com taxa de crescimento anual entre 3 e 3,5\% (Bernardes, 2007). A Amazônia detém a maior parte dos búfalos domésticos do Brasil, onde são registradas ocorrências climáticas que ocasionam perdas significativas dos animais menos adaptados às condições locais. Apesar da adaptabilidade dos bubalinos às mais variadas condições de ambiente, esses animais possuem particularidades estruturais específicas, como forte concentração de melanina na pele e no pelo, baixa quantidade de glândulas sudoríparas, baixa densidade de pelos, e são sensíveis à radiação solar. Seu sistema termorregulador é eficiente, porém, quando submetidos à temperatura ambiente

Pesq. agropec. bras., Brasília, v.46, n.10, p.1364-1371, out. 2011 
de $36^{\circ} \mathrm{C}$ ou mais elevadas, apresentam estresse térmico (Silanikove, 2000; Guimarães et al., 2001; Marai \& Haeed, 2010a, 2010b), o que compromete a produtividade individual.

Uma alternativa para reduzir os efeitos das condições climáticas estressantes para os animais é a adoção de sistemas silvipastoris que incorporam o uso de espécies florestais às pastagens. Além de conferir maior conforto aos animais, com consequente aumento da produtividade e redução de custos, esses sistemas são capazes de aumentar a biodiversidade em regiões alteradas pelo uso inapropriado do solo (Leme et al., 2005) e proporcionam a intensificação da agropecuária, associada à maior rentabilidade, decorrente da comercialização de produtos cárneos, lácteos e seus derivados, que agregam valor à propriedade (Falesi \& Galeão, 2002).

O objetivo deste trabalho foi avaliar os efeitos do sistema silvipastoril no estresse térmico e nas respostas fisiológicas de búfalas, criadas ao sol e à sombra, nas condições quentes e úmidas de Belém, PA.

\section{Material e Métodos}

O experimento foi realizado na Unidade de Pesquisa Animal Senador Álvaro Adolpho (0126'03"S e $48^{\circ} 26^{\prime} 03^{\prime \prime} \mathrm{W}$ e altitude de $8 \mathrm{~m}$ ), da Embrapa Amazônia Oriental, Belém, PA, de janeiro a dezembro de 2009. O clima do local é do tipo Afi segundo a classificação de Köppen, com precipitação pluvial média de $3.001,3 \mathrm{~mm}$ ao ano, bem distribuída ao longo dos meses, com período mais chuvoso de janeiro a junho e menos chuvoso, de julho a dezembro. A temperatura média anual é de $26^{\circ} \mathrm{C}$, com umidade relativa do ar em torno de $86 \%$ e insolação anual de 2.400 horas (Bastos et al., 2002). Os dados mensais de temperatura e umidade relativa do ar e precipitação pluvial, no período experimental, de janeiro a dezembro de 2009 , bem como as médias climatólogicas para o período 1967 a 1996, em Belém, PA (Bastos et al., 2002), estão apresentados na Figura 1 A e B. O solo é do tipo Latossolo Amarelo, fase pedregosa I, de textura argilosa.

Foram utilizadas 20 búfalas Murrah, entre quatro e cinco anos de idade, com peso médio de 479,6 kg, cíclicas, não gestantes, não lactantes e clinicamente saudáveis, distribuídas aleatoriamente em dois grupos de dez animais cada um: CS, com sombra e SS, sem sombra. Para a formação desses grupos, foi mantida uniformidade quanto à idade dos animais, escore corporal e condição reprodutiva.

A área experimental de aproximadamente 13 ha foi dividida em seis piquetes. Ambos os grupos permaneceram em pastejo rotacionado intensivo, com 14 dias de ocupação e 28 dias de diferimento. O grupo CS esteve em piquetes com sombra de árvores da leguminosa Racosperma mangium (ex-Acacia), em sistema silvipastoril. Essa espécie florestal foi plantada em 2005, com $4 \mathrm{~m}$ de espaçamento, entre as cercas perimetrais e divisórias, as quais eram eletrificadas com dois fios. O grupo SS foi mantido sem acesso à sombra. Os animais passaram por período de adaptação de 14 dias. A alimentação oferecida constituiu-se, exclusivamente, de pasto com a gramínea Urochloa humidicola, com acesso à água para beber e sal mineral à vontade.

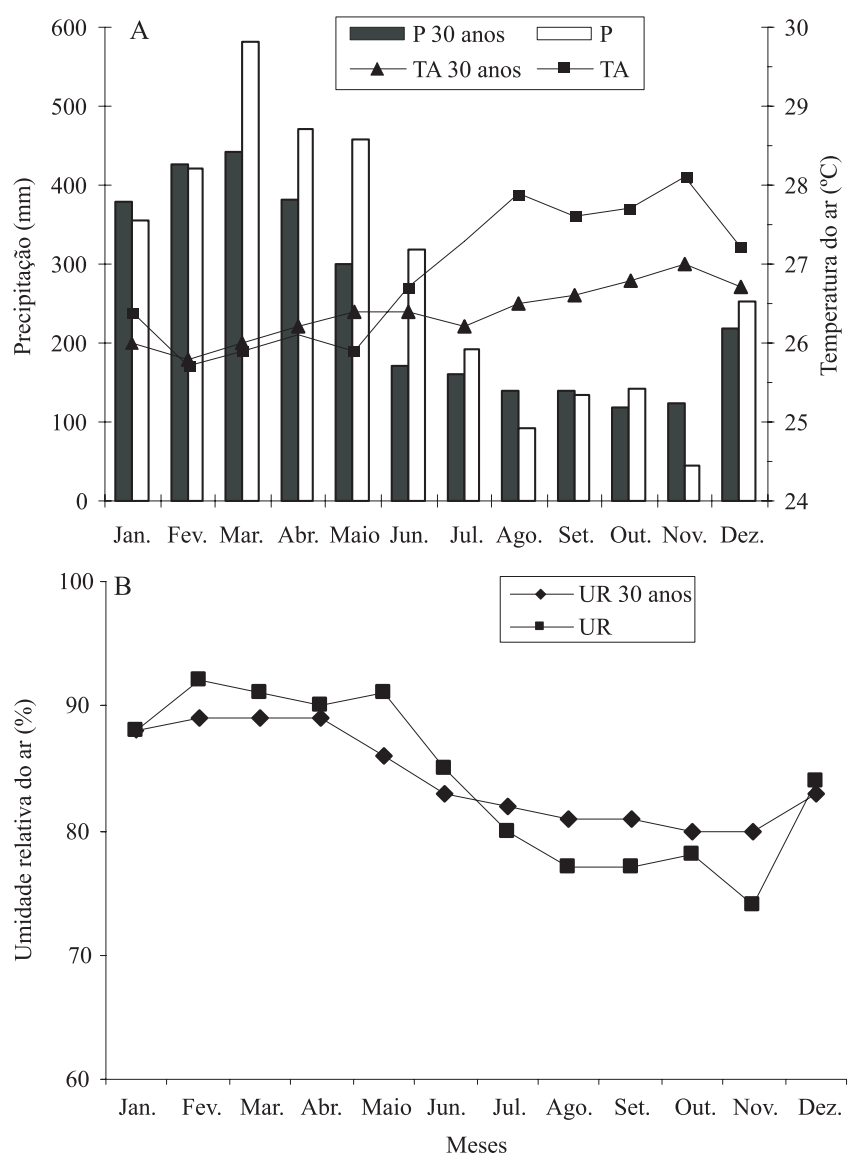

Figura 1. Médias mensais de precipitação pluvial (P), temperatura do ar (TA, A) e umidade relativa do ar (UR, B) no período de janeiro a dezembro de 2009, e as respectivas médias históricas entre 1967 e 1996. Adaptado de Bastos et al. (2002). 
Os dados meteorológicos foram registrados com auxílio de um medidor de estresse térmico modelo TGD-300 (Instruterm, São Paulo, Brasil), instalado no microclima de cada piquete para cada tratamento (grupo CS e grupo SS). Foram registrados dados de temperatura e umidade relativa do ar, temperatura de ponto de orvalho e temperatura de globo negro. As leituras das variáveis ambientais foram realizadas das 6 às 7 h e das 12 às 13h, na ocasião das coletas das variáveis fisiológicas, em que os dados eram registrados em "data logger" a cada minuto.

O índice de temperatura de globo e umidade (ITGU) foi calculado de acordo com o proposto por Buffington et al. (1981), pela equação:

$$
\mathrm{ITGU}=\mathrm{t}_{\mathrm{gn}}+0,36 \mathrm{t}_{\mathrm{po}}+41,5,
$$

em que: $t_{g n}$ é a temperatura de globo negro ao sol e $t_{\mathrm{po}}$ é a temperatura do ponto de orvalho. $\mathrm{O}$ valor do ITGU considera os efeitos de temperatura de bulbo seco, de umidade relativa do ar, de radiação solar e de movimentação do ar, uma vez que a temperatura de globo negro, que compõe a fórmula desse índice, indica os efeitos da combinação dessas variáveis meteorológicas (Kelly \& Bond, 1971; Marcheto et al., 2002), além de fornecer uma medida indireta do calor radiante do ambiente. Os valores de ITGU são utilizados para avaliar a situação de conforto térmico de animais com a seguinte escala: até 74 , conforto; de 74 a 78, alerta; de 79 a 84, perigosa; e acima de 84, emergência (Souza et al., 2002).

As variáveis fisiológicas estudadas foram: temperatura retal (TR), temperatura da superfície corporal (TSC), frequência respiratória (FR) e frequência cardíaca (FC), aferidas a cada três dias, no período da manhã entre 6 e $7 \mathrm{~h}$, e à tarde entre $12 \mathrm{e}$ 13h. Para obtenção da TR, foi utilizado um termômetro clínico veterinário, com escala até $44^{\circ} \mathrm{C}$, com resultado da leitura expresso em graus centígrados. A TSC foi obtida com auxílio de termômetro de infravermelho, modelo TD-965 (Instrutemp, São Paulo, Brasil) acionado em distância máxima de $1 \mathrm{~m}$ dos pontos de mensuração no animal, que foram a fronte, lado esquerdo do tórax e flanco esquerdo, tendo-se obtido a média desses valores. A FR foi obtida por inspeção e contagem dos movimentos tóraxico-abdominais, durante 1 min, e a FC foi determinada por auscultação e contagem, com o auxílio de estetoscópio clínico veterinário, durante $1 \mathrm{~min}$.

Os dados das variáveis fisiológicas foram expressos em médias e desvio-padrão. Ao analisar os dados climáticos do microclima de cada tratamento (grupos SS e CS), observou-se a existência de uma fase de transição entre o período mais e o menos chuvoso do ano, principalmente à tarde, em maio, junho e julho (Figura 1). Neste período, houve diminuição significativa da umidade relativa do ar e da pluviosidade, bem como sensível aumento da temperatura do ar. Assim, os dados foram organizados em três períodos do ano: período mais chuvoso (janeiro a abril), período de transição (maio a julho) e período menos chuvoso (agosto a dezembro). O objetivo para essa divisão é detectar se as condições meteorológicas desses períodos influenciam as respostas fisiológicas das búfalas.

Utilizou-se o delineamento experimental inteiramente casualizado, em arranjo fatorial de dois tratamentos (com e sem sombra), três períodos do ano (mais chuvoso, transição e menos chuvoso) e dois turnos (manhã e tarde). As análises de variância foram feitas com o modelo GLM do programa estatístico SYSTAT, versão 12, para verificar o efeito de tratamento (grupo CS e grupo SS), turno do dia (manhã e tarde), períodos do ano (mais chuvoso, transição e menos chuvoso), e de suas interações, sobre os parâmetros fisiológicos acima citados. As médias foram comparadas pelo teste de Tukey, a 5\% de probabilidade. Foram feitas correlações lineares de Pearson, para verificar a magnitude e direção da proporcionalidade das diversas variáveis fisiológicas, tendo-se observado a independência das variâncias dos pares de observações utilizados.

\section{Resultados e Discussão}

Todos os valores de ITGU encontrados mostram uma situação de desconforto para os animais (Figura 2). Em todas as situações, encontrou-se uma condição térmica bem acima daquela considerada de conforto (ITGU $=74)$, o que sugere que os animais poderiam estar em condições de estresse calórico tanto na sombra como no sol, em que a situação no sol, no turno da tarde, foi bem mais estressante. No período mais chuvoso do ano, o ITGU esteve próximo ao registrado por Santos et al. (2005), no Semiárido paraibano, de 85,5 no turno da tarde. Entretanto, nos períodos 
de transição e menos chuvoso do ano, os valores do presente trabalho estiveram acima dos citados por esses autores, principalmente em animais sem acesso à sombra.

Em todos os períodos do ano e tratamentos (grupos CS e SS), a temperatura retal no turno da tarde foi superior ao da manhã (Tabela 1). Valores mais elevados de ITGU à tarde mostram que, neste turno, os animais estão mais sujeitos à exposição à radiação solar direta $\mathrm{e}$ indireta, o que pode ter causado condições ambientais desfavoráveis. Gudev et al. (2007b) afirmam que essa elevação da TR, em ambiente quente, indica que os mecanismos de liberação de calor se tornaram

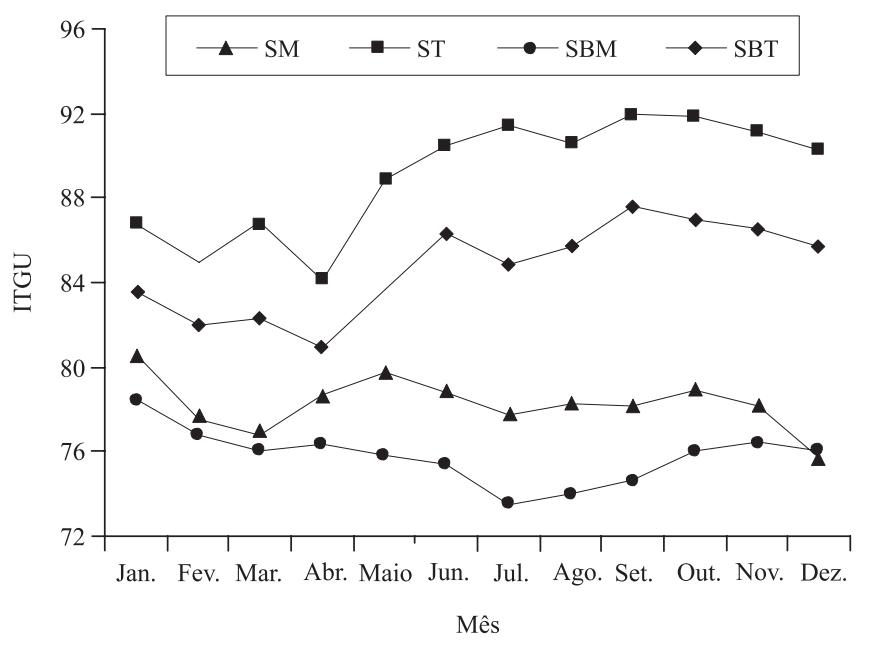

Figura 2. Variação da média do índice de temperatura de globo e umidade (ITGU), ao sol e à sombra, pela manhã e à tarde, no período experimental, de janeiro a dezembro de 2009, em Belém, PA. (SM: grupo SS, manhã; ST: grupo SS, tarde; SBM: grupo CS, manhã, e SBT: grupo CS, tarde). insuficientes para manter a homeotermia. Pesquisas realizadas por Magalhães et al. (2000), com bovinos e bubalinos, nas mesmas condições climáticas, apresentaram resultados semelhantes, em que a temperatura retal dos bubalinos passou de $38^{\circ} \mathrm{C}$, pela manhã, para $39,3^{\circ} \mathrm{C}$, à tarde.

Em ambos os grupos e turnos, houve diferença significativa entre os períodos do ano. No grupo SS, no turno da manhã, os valores mais elevados da temperatura retal ocorreram no período mais chuvoso. No grupo CS, os maiores valores ocorreram no período mais chuvoso e no período de transição. No turno da tarde, observouse a mesma tendência para ambos os grupos. Isso pode ter ocorrido em razão da elevada umidade relativa do ar, que ocorre na região durante esse período, o que fez com que os animais apresentassem dificuldades em trocar calor com o meio e os levasse à condição de estresse térmico (Silanikove, 2000).

Houve diferenças significativas entre tratamentos, no turno da tarde, nos períodos mais e menos chuvoso, em que o grupo SS apresentou valores maiores de temperatura retal. Isto, provavelmente, se deve aos mais elevados índices de ITGU que ocorreram nesse tratamento, o que indica que os animais estavam expostos a maiores valores de radiação solar direta, pois não tinham acesso à sombra. Paranhos da Costa (2000) demonstrou que búfalos criados em pastagem, sem acesso à sombra, apresentam aumento significativo nos valores da temperatura retal (de 38,3 para $39,1^{\circ} \mathrm{C}$ ) e frequência respiratória (de 22,6 para 48,4 movimentos por min), como forma de dissipar o excesso de calor corporal, em decorrência do estresse térmico, o que prejudica seu potencial produtivo.

Tabela 1. Médias \pm desvio padrão e máximas da temperatura $\left({ }^{\circ} \mathrm{C}\right)$ retal de búfalas Murrah, criadas a pleno sol (grupo SS) e com acesso à sombra (grupo CS), pela manhã e à tarde, de acordo com os períodos do ano de $2009^{(1)}$.

\begin{tabular}{|c|c|c|c|c|c|c|c|c|}
\hline \multirow[t]{3}{*}{ Período } & \multicolumn{4}{|c|}{ Temperatura retal $\left({ }^{\circ} \mathrm{C}\right)$} & \multicolumn{4}{|c|}{ Temperatura corporal $\left({ }^{\circ} \mathrm{C}\right)$} \\
\hline & \multicolumn{2}{|c|}{ Manhã } & \multicolumn{2}{|c|}{ Tarde } & \multicolumn{2}{|c|}{ Manhã } & \multicolumn{2}{|c|}{ Tarde } \\
\hline & Máxima & Média & Máxima & Média & Máxima & Média & Máxima & Média \\
\hline & \multicolumn{8}{|c|}{ Grupo SS } \\
\hline Mais chuvoso & 38,6 & $38,4 \pm 0,1 \mathrm{aBns}$ & 39,0 & $38,8 \pm 0,1 \mathrm{aA} *$ & 32,5 & $31,3 \pm 0,4 \mathrm{aBns}$ & 34,3 & $34,1 \pm 0,2 \mathrm{cA} *$ \\
\hline Transição & 38,4 & $38,3 \pm 0,1 \mathrm{bBns}$ & 38,7 & $38,6 \pm 0,1 \mathrm{bAns}$ & 31,0 & $29,1 \pm 0,7 \mathrm{bBns}$ & 35,1 & $34,6 \pm 0,3 \mathrm{bA} *$ \\
\hline \multirow[t]{2}{*}{ Menos chuvoso } & 38,3 & $38,2 \pm 0,1 \mathrm{cBns}$ & 38,8 & $38,6 \pm 0,1 \mathrm{bA} *$ & 31,1 & $29,4 \pm 0,7 \mathrm{bB} *$ & 37,8 & $37,0 \pm 0,3 \mathrm{aA} *$ \\
\hline & \multicolumn{8}{|c|}{ Grupo CS } \\
\hline Mais chuvoso & 38,7 & $38,4 \pm 0,2 \mathrm{aB}$ & 38,9 & $38,6 \pm 0,1 \mathrm{aA}$ & 31,8 & $31,2 \pm 0,5 \mathrm{aB}$ & 33,7 & $33,35 \pm 0,3 \mathrm{bA}$ \\
\hline Transição & 38,6 & $38,4 \pm 0,1 \mathrm{aB}$ & 38,8 & $38,6 \pm 0,1 \mathrm{aA}$ & 30,3 & $28,9 \pm 0,9 \mathrm{bB}$ & 33,7 & $33,22 \pm 0,4 \mathrm{bA}$ \\
\hline Menos chuvoso & 38,3 & $38,2 \pm 0,1 \mathrm{bB}$ & 38,6 & $38,4 \pm 0,1 \mathrm{bA}$ & 30,1 & $28,9 \pm 0,6 \mathrm{bB}$ & 35,2 & $34,73 \pm 0,4 \mathrm{aA}$ \\
\hline
\end{tabular}

(1)Médias seguidas de letras iguais, em cada grupo, minúsculas nas colunas e maiúsculas nas linhas, não diferem entre si pelo teste de Tukey, a $5 \%$ de probabilidade. ${ }^{n s}$ Não significativo. *Diferença significativa pelo teste de Tukey, a $5 \%$ de probabilidade, entre os grupos sem e com sombra, no mesmo turno. 
Entre os períodos do ano, houve diferenças da temperatura da superfície corporal nos grupos e turnos, em que os animais do grupo SS, no turno da tarde, apresentaram os maiores valores (Tabela 1), provavelmente por estarem mais expostos à radiação solar difusa, conforme indicam os maiores valores de ITGU nesse turno. Os maiores valores de temperatura da superfície corporal do turno da manhã, em ambos os grupos, foram observados no período mais chuvoso. Entretanto, no turno da tarde, os maiores valores foram encontrados no período menos chuvoso do ano, quando a temperatura do ar foi mais elevada e, sob essas condições, há um aumento do fluxo sanguíneo do núcleo central para a periferia corporal, na tentativa de eliminar calor, o que contribui para a elevação da temperatura da superfície corporal.

Quanto à frequência respiratória dos animais, houve interação significativa entre período $\mathrm{x}$ turno e período $\mathrm{x}$ tratamento (Tabela 2), e tratamento $\mathrm{x}$ turno (Tabela 3). Em todos os períodos do ano, houve diferenças significativas entre os turnos, com a frequência respiratória do turno da tarde mais elevada (Tabela 2). Segundo Guimarães et al. (2001) e Ferreira et al. (2006), em situações de estresse térmico, essa variável fisiológica apresenta valores elevados, antes mesmo que haja aumento dos valores da temperatura retal. No turno da manhã, os maiores valores da frequência respiratória foram encontrados no período menos chuvoso. No turno da tarde, os maiores valores ocorreram nos períodos mais e menos chuvoso do ano, com valores menores no período de transição, o que indica ser esse o período de maior conforto para os animais.

Houve diferenças significativas da frequência respiratória entre os tratamentos, dentro de cada período do ano, e a diferença ocorreu no período mais chuvoso, em que o grupo SS apresentou valores maiores (Tabela 2). Esses resultados estão de acordo com os de Gudev et al. (2007a), que observaram que a exposição de fêmeas bubalinas, sob radiação solar direta, causou estresse térmico, indicado pelo aumento dos níveis de FR.

No grupo SS, nos períodos mais e menos chuvosos, os animais apresentaram os valores mais elevados de frequência respiratória. Esse valor elevado no período mais chuvoso do ano, pode ter ocorrido em razão da dificuldade desses animais de dissipar calor por evaporação, pois, nesse período, a umidade relativa do ar é bastante elevada. Em búfalos, a perda de calor pelo ar expirado é mais importante que pela transpiração, pois possuem baixa eficiência na perda de calor pelas vias cutâneas (Guimarães et al., 2001; Gudev et al., 2007b). No entanto, o grupo CS apresentou maiores valores somente no período menos chuvoso do ano. De acordo com Guimarães et al. (2001), à medida que a temperatura do ar aumenta, a frequencia respiratória dos bubalinos se eleva de 22 para mais de 48 movimentos por min, a temperaturas de 28,3 a $34,7^{\circ} \mathrm{C}$, respectivamente.

Em ambos os tratamentos, observaram-se diferenças significativas entre turnos e grupos, e no turno da tarde e no grupo SS, a frequência respiratória foi maior (Tabela 3). O fornecimento de sombra na pastagem contribuiu para a redução da frequência respiratória, provavelmente por melhorar o conforto térmico no ambiente (Marai \& Haeeb, 2010a).

Em todos os períodos do ano, foram constatadas diferenças significativas entre os turnos, para os dois grupos, e a frequência cardíaca do turno da tarde foi superior à da manhã (Tabela 4). Quando o organismo está em estresse térmico, ocorre uma vasodilatação periférica que resulta em queda da pressão arterial, compensada por incremento no trabalho cardíaco (Marai \& Haeeb, 2010b). Dentro dos turnos, observou-se superioridade nos valores de frequência cardíaca, no período mais chuvoso do ano. Isso pode ter ocorrido em consequência da excessiva umidade relativa do ar que, quando combinada com a ainda

Tabela 2. Médias \pm desvio-padrão e máximas da frequência respiratória (movimentos por minuto) de búfalas Murrah, pela manhã e à tarde, criadas a pleno sol (grupo SS) e com acesso à sombra (grupo CS), de acordo com os períodos do ano de $2009^{(1)}$.

\begin{tabular}{|c|c|c|c|c|c|c|c|c|}
\hline \multirow[t]{2}{*}{ Período } & \multicolumn{2}{|c|}{ Manhã } & \multicolumn{2}{|c|}{ Tarde } & \multicolumn{2}{|c|}{ Grupo SS } & \multicolumn{2}{|c|}{ Grupo CS } \\
\hline & Máxima & Média & Máxima & Média & Máxima & Média & Máxima & Média \\
\hline Mais chuvoso & 32,1 & $28,5 \pm 1,9 \mathrm{bB}$ & 42,6 & $34,0 \pm 3,7 \mathrm{aA}$ & 42,0 & $32,1 \pm 4,2 \mathrm{aA}$ & 42,6 & $30,4 \pm 3,8 \mathrm{bB}$ \\
\hline Transição & 31,0 & $28,3 \pm 1,1 \mathrm{bB}$ & 36,1 & $32,1 \pm 1,7 \mathrm{bA}$ & 34,0 & $30,6 \pm 2,3 \mathrm{bA}$ & 36,1 & $29,7 \pm 2,5 \mathrm{bA}$ \\
\hline Menos chuvoso & 31,1 & $29,8 \pm 1,1 \mathrm{aB}$ & 38,9 & $34,4 \pm 1,8 \mathrm{aA}$ & 39,0 & $32,7 \pm 3,0 \mathrm{aA}$ & 37,3 & $31,5 \pm 2,5 \mathrm{aA}$ \\
\hline
\end{tabular}

${ }^{(1)}$ Médias seguidas de letras iguais, minúsculas nas colunas e maiúsculas nas linhas, na comparação entre turnos e grupos, não diferem pelo teste de Tukey, a $5 \%$ de probabilidade. 
elevada temperatura ambiente (Marai et al., 2009), clima típico da região, dificulta a troca de calor do animal com o meio, levando-o a acionar seu sistema termorregulatório, para manter a temperatura corporal em níveis normais (Silanikove, 2000). Em todos os períodos do ano, houve diferenças da frequência cardíaca entre os grupos, em que os animais do grupo SS apresentavam os maiores valores, exceto no período de transição, no turno da tarde. Esses resultados podem estar relacionados aos maiores valores de ITGU encontrados durante esse turno, que retrata em um só valor, os efeitos da temperatura de bulbo seco, da umidade relativa do ar, do nível de radiação solar e de movimentação do ar. De acordo com Castro et al. (2008), a disponibilidade de sombra no sistema silvipastoril, que protege os animais da incidência direta da radiação solar, confere sensação térmica de menor temperatura e, consequentemente, propicia maior conforto térmico.

Tabela 3. Médias \pm desvio-padrão e máximas da frequência respiratória (movimentos por minuto) de búfalas Murrah, criadas a pleno sol (grupo SS) e com acesso à sombra (grupo CS), pela manhã e à tarde, no ano de $2009^{(1)}$.

\begin{tabular}{lccccc}
\hline Período & \multicolumn{2}{c}{ Manhã } & & \multicolumn{2}{c}{ Tarde } \\
\cline { 2 - 3 } \cline { 5 - 6 } & Máxima & Média & & Máxima & Média \\
\hline Grupo SS & 31,2 & $29,2 \pm 1,4 \mathrm{aB}$ & & 42,0 & $34,4 \pm 2,5 \mathrm{aA}$ \\
Grupo CS & 32,1 & $28,5 \pm 1,6 \mathrm{aB}$ & & 42,6 & $32,6 \pm 2,7 \mathrm{bA}$ \\
\hline
\end{tabular}

(1)Médias seguidas de letras iguais, minúsculas nas colunas e maiúsculas nas linhas, não diferem, pelo teste de Tukey, a 5\% de probabilidade.

Tabela 4. Médias \pm desvio-padrão e máximas da frequência cardíaca (batimentos por minuto) de búfalas Murrah, criadas a pleno sol (grupo SS) e com acesso à sombra (grupo CS), pela manhã e à tarde, de acordo com os períodos do ano de $2009^{(1)}$.

\begin{tabular}{lccccc}
\hline Período & \multicolumn{2}{c}{ Manhã } & & \multicolumn{2}{c}{ Tarde } \\
\cline { 2 - 3 } & Máxima & Média & & Máxima & Média \\
\hline \multirow{4}{*}{ Mais chuvoso } & 76,0 & $67,7 \pm 5,0 \mathrm{aB}^{*}$ & 81,0 & $73,9 \pm 4,3 \mathrm{aA} *$ \\
Transição & 68,2 & $60,6 \pm 3,7 \mathrm{bB}^{*}$ & & 75,1 & $65,7 \pm 4,2 \mathrm{bAns}$ \\
Menos chuvoso & 65,7 & $61,0 \pm 2,5 \mathrm{bB} *$ & 70,7 & $63,2 \pm 3,0 \mathrm{cA} *$ \\
\hline \multicolumn{5}{c}{ Grupo CS } \\
Mais chuvoso & 72,4 & $61,1 \pm 5,6 \mathrm{aB}$ & 78,6 & $65,5 \pm 6,4 \mathrm{aA}$ \\
Transição & 65,0 & $54,5 \pm 5,5 \mathrm{bB}$ & & 74,6 & $63,2 \pm 6,5 \mathrm{bA}$ \\
Menos chuvoso & 61,8 & $55,5 \pm 3,9 \mathrm{bB}$ & 65,6 & $58,1 \pm 4,3 \mathrm{cA}$ \\
\hline
\end{tabular}

(1)Médias seguidas de letras iguais, em cada grupo, minúsculas nas colunas e maiúsculas nas linhas, não diferem pelo teste de Tukey, a $5 \%$ de probabilidade. ${ }^{\text {ns }}$ Não significativo. $*$ Diferença significativa pelo teste de Tukey, a $5 \%$ de probabilidade, entre os grupos sem e com sombra, no mesmo turno.
Considerando-se a divisão dos períodos do ano, tradicionalmente conhecidos em Belém, PA, na Tabela 5 estão apresentadas as correlações entre variáveis climáticas e fisiológicas de búfalas Murrah, nos períodos mais (janeiro a junho) e menos chuvoso do ano (julho a dezembro). Verifica-se que a temperatura retal apresentou, nos dois períodos, correlação significativa positiva com a temperatura do ar e ITGU, e negativa com a umidade relativa do ar. Costa (2007) também constatou correlação significativa positiva entre a temperatura retal e ITGU $(r=0,486, p<0,01)$ em novilhas bubalinas, no Agreste de Pernambuco. Para a temperatura superficial da pele, em ambos os períodos, foram observadas correlações significativas positivas com a temperatura do ar e ITGU, e negativas com a umidade relativa do ar. Em Pernambuco, Costa (2007) encontrou resultados semelhantes em novilhas bubalinas, com correlação significativa positiva entre a temperatura superficial da pele e o ITGU $(\mathrm{r}=0,440, \mathrm{p}<0,01)$. A frequência respiratória apresentou correlação significativa positiva com a temperatura do ar e o ITGU, e negativa com a umidade relativa do ar, em ambos os períodos. Costa (2007), também encontrou correlação significativa positiva entre a frequência respiratória e o ITGU $(r=0,496, p<0,01)$. A frequência cardíaca, nos dois períodos do ano, também apresentou correlações significativas e positivas com a temperatura do ar e o ITGU, e significativa negativa com a umidade relativa do ar, somente no período mais chuvoso do ano.

A temperatura superficial da pele foi altamente correlacionada às variáveis climáticas, o que mostra que esta variável é um bom indicador para se determinar o estresse pelo calor em bubalinos. Os valores de coeficiente de correlação, entre

Tabela 5. Correlação linear entre as variáveis fisiológicas de búfalas Murrah e climáticas, nos períodos menos e mais chuvosos do ano de $2009^{(1)}$.

\begin{tabular}{lccccccc}
\hline Variável & \multicolumn{3}{c}{ Menos chuvoso } & & \multicolumn{3}{c}{ Mais chuvoso } \\
\cline { 2 - 4 } \cline { 7 - 8 } & TA & UR & ITGU & & TA & UR & ITGU \\
\hline TR & $0,59^{* *}$ & $-0,52^{* *}$ & $0,59^{* *}$ & & $0,52^{* *}$ & $-0,39^{* *}$ & $0,50^{* *}$ \\
TSC & $0,89^{* *}$ & $-0,87^{* *}$ & $0,90^{* *}$ & & $0,77^{* *}$ & $-0,61 * *$ & $0,75^{* *}$ \\
FR & $0,46^{* *}$ & $-0,42^{* *}$ & $0,48^{* *}$ & & $0,42^{* *}$ & $-0,40^{* *}$ & $0,40^{* *}$ \\
FC & $0,27^{* *}$ & $-0,22 *$ & $0,30^{* *}$ & & $0,37^{* *}$ & $-0,30^{*}$ & $0,35^{* *}$ \\
\hline
\end{tabular}

(1) TR, temperatura retal; TSC, temperatura da superfície corporal; FR, frequência respiratória; FC, frequência cardíaca; TA, temperatura do ar; UR, umidade relativa do ar; ITGU, índice de temperatura de globo e umidade. * e **Significativo a 1 e $5 \%$, respectivamente. 
temperatura retal e variáveis meteorológicas, foram maiores que aqueles obtidos nas correlações entre frequência respiratória e cardíaca e tais variáveis. Esse fato evidencia que a temperatura retal é um indicador melhor de estresse térmico do que a frequência respiratória e cardíaca.

\section{Conclusões}

1. Búfalas Murrah com acesso à sombra de árvores, cujo microclima apresenta menores valores de temperatura do ar, índice de temperatura do globo e umidade relativa do ar, estão em melhores condições de conforto térmico, o que mostra a eficiência do sistema silvipastoril na promoção de conforto térmico de búfalos.

2. Independentemente do período do ano, as búfalas Murrah estão sujeitas a ambiente de desconforto térmico, e o período menos chuvoso do ano é o mais propício a causar estresse térmico nos animais, com maiores valores do índice de temperatura do globo e umidade no turno da tarde.

3. As búfalas Murrah apresentam os maiores valores de temperatura retal e superficial da pele e frequência respiratória e cardíaca, no turno da tarde, o que mostra que os animais estão mais propícios a apresentar estresse térmico nesse turno.

4. A temperatura ambiente é, isoladamente, o fator de maior impacto sobre o bem estar das búfalas Murrah.

\section{Agradecimentos}

À Superintendência de Desenvolvimento da Amazônia, à Embrapa Amazônia Oriental, à Universidade Federal Rural da Amazônia e à Coordenação de Aperfeiçoamento de Pessoal de Nível Superior, pelo apoio financeiro.

\section{Referências}

BASTOS, T.X.; PACHECO, N.A.; NECHET, D.; SÁ, T.D. de A. Aspectos climáticos de Belém nos últimos cem anos. Belém: Embrapa Amazônia Oriental, 2002. 31p. (Embrapa Amazônia Oriental. Documentos, 128).

BERNARDES, O. Bubalinocultura no Brasil: situação e importância econômica. Revista Brasileira de Reprodução Animal, v.31, p.293-298, 2007.

BUFFINGTON, D.E.; COLAZZO-AROCHO, A.; CATON, G.H. Black globe humidity comfort index (BGHI) as comfort equation for dairy cows. Transaction of the American Society of Agricultural Engineering, v.24, p.711-714, 1981.

CASTRO, A.C.; LOURENÇO JÚNIOR, J. de B.; SANTOS, N. de F.A. dos; MONTEIRO, E.M.M.; AVIZ, M.A.B. de; GARCIA, A.R. Sistema silvipastoril na Amazônia: ferramenta para elevar o desempenho produtivo de búfalos. Ciência Rural, v.38, p.2395-2402, 2008.

COSTA, L.A.B. Índices de conforto térmico e adaptabilidade de fêmeas bubalinas em pastejo no Agreste de Pernambuco. 2007. 52p. Dissertação (Mestrado) - Universidade Federal Rural de Pernambuco, Recife.

FALESI, I.C.; GALEÃO, R.R. Recuperação de áreas antropizadas da mesorregião do nordeste paraense através de sistemas agroflorestais. Belém: Emater, 2002. 25p. (Emater. Documentos, 1).

FERREIRA, F.; PIRES, M.F.A.; MARTINEZ, M.L.; COELHO, S.G.; CARVALHO, A.U.; FERREIRA, P.M.; FACURY FILHO, E.J.; CAMPOS, E.W. Parâmetros fisiológicos de bovinos cruzados submetidos ao estresse calórico. Arquivo Brasileiro de Medicina Veterinária e Zootecnia, v.58, p.732-738, 2006.

GUDEV, D.; POPOVA-RALCHEVA, S.; MONEVA, P.; ALEKSIEV, Y.; PEEVA, T.; ILIEVA, Y.; PENCHEV, P. Effect of heat-stress on some physiological and biochemical parameters in buffaloes. Italian Journal of Animal Science, v.6, p.1325-1328, 2007a.

GUDEV,D.;POPOVA-RALCHEVA,S.;MONEVA,P.;ALEKSIEV, Y.; PEEVA, T.; PENCHEV, P.; ILIEVA, Y. Physiological indices in buffaloes exposed to sun. Archiva Zootechnica, v.10, p.127-133, 2007b.

GUIMARÃES, C.M.C.; FALCO, J.E.; TITTO, E.A.L.; FRANZOLIN NETO, R.; MUNIZ, J.A. Termorregulação em bubalinos submetidos a duas temperaturas de ar e duas proporções de volumoso: concentrado. Ciência e Agrotecnologia, v.25, p.437-443, 2001 .

KELLY, C.F.; BOND, T.E. Bioclimatic factors and their measurement. In: NATIONAL ACADEMY OF SCIENCES. A guide to environmental research on animals. Washington: National Academy of Sciences, 1971. p.7-92.

LEME, T.M.S.P.; PIRES, M. de F.A.; VERNEQUE, R. da S.; ALVIM, M.J.; AROEIRA, L.J.M. Comportamento de vacas mestiças Holandês x Zebu, em pastagem de Brachiaria decumbens em sistema silvipastoril. Ciência e Agrotecnologia, v.29, p.668-675, 2005.

MAGALHÃES, J.A.; TAKIGAWA, R.M.; TOWNSEND, C.R.; COSTA, N.L.; PEREIRA, R.G.A. Tolerância de bovídeos à temperatura e umidade do trópico úmido. Revista Científica de Produção Animal, v.2, p.162-167, 2000.

MARAI, I.F.M.; DAADER, A.H.; SOLIMAN, A.M.; EL-MENSHAWY, S.M.S. Non-genetic factors affecting growth and reproduction traits of buffaloes under dry management housing (in sub-tropical environment) in Egypt. Livestock Research for Rural Development, v.21, 2009. Available at: $<$ http://www.lrrd.org/lrrd21/3/mara21030.htm>. Accessed on: 18 Apr. 2011. 
MARAI, I.F.M.; HAEEB, A.A.M. Buffaloes reproductive and productive traits as affected by heat stress. Tropical and Subtropical Agroecosystems, v.12, p.193-217, 2010a.

MARAI, I.F.M; HAEEB, A.A.M. Buffalo's biological functions as affected by heat stress - a review. Livestock Science, v.127, p.89-109, 2010b.

MARCHETO, F.G.; NÄÄS, I. de A.; SALGADO, D.D'A.; SOUZA, S.R.L. de. Efeito das temperaturas de bulbo seco e de globo negro e do índice de temperatura e umidade, em vacas em produção alojadas em sistema de free-stall. Brazilian Journal of Veterinary Research and Animal Science, v.39, p.320-323, 2002.

PARANHOS DA COSTA, M.J.R. Ambiência na produção de bubalinos destinados ao abate. In: ENCONTRO ANUAL DE
ETOLOGIA, 2000, Florianópolis, SC. Anais. Florianópolis: Sociedade Brasileira de Etologia, 2000. p.26-42.

SANTOS, F.C.B. dos; SOUZA, B.B. de; ALFARO, C.E.P.; CÉZAR, M.F.; PIMENTA FILHO, E.C.; ACOSTA, A.A.A.; SANTOS, J.R.S. dos. Adaptabilidade de caprinos exóticos e naturalizados ao clima semi-árido do Nordeste brasileiro. Ciência e Agrotecnologia, v.29, p.142-149, 2005.

SILANIKOVE, N. Effects of heat stress on the welfare of extensively managed domestic ruminants. Livestock Production Science, v.67, p.1-18, 2000.

SOUZA, C. de F.; TINÔCO, I. de F.F.; BAÊTA, F. da C.; FERREIRA, W.P.M.; SILVA, R.S. da. Avaliação de materiais alternativos para confecção de termômetro de globo. Ciência e Agrotecnologia, v.26, p.157-164, 2002.

Recebido em 10 de maio de 2010 e aprovado em 31 de agosto de 2011 